\title{
Research on Satisfaction of Postgraduate Education Based on Structural Equation Model
}

\author{
Shuxin Guo* \\ College of Management Science and Information \\ Engineering \\ Jilin University of Finance and Economics \\ Changchun, P.R.China \\ *Corresponding author
}

\author{
Mengli Li \\ College of Management Science and Information \\ Engineering \\ Jilin University of Finance and Economics \\ Changchun, China
}

\begin{abstract}
As the main body of higher education implementation, it is of great significance to study the students' satisfaction with education to reveal the quality of higher education and reflect the completion of the goal of higher education in China, it is an important part of higher education evaluation system. In this paper, we take the education of master's degree in the higher education talent development system as the research object, and use the structural equation model to study the evaluation of the professional master's education satisfaction in the universities in China. Through the analys is of the concepts of structural equation model, education satisfaction and other related concepts, we comprehensively discuss the construction of the structural equation model for the satisfaction evaluation of master's education. Finally, based on the above research, scientific suggestions are given on the promotion strategy of graduate education satisfaction.
\end{abstract}

Keywords-Higher education; Master's degree; Education satisfaction; Structural equation model

\section{INTRODUCTION}

Education satisfaction was originally developed from customer satisfaction, and it is intended to explore the subjective emotions reflected by students in the process of receiving educational services through a comprehensive analysis of a series of quantitative indicators. In recent years, the study of college student satisfaction has been an important topic in the study of the development and direction of Chinese education, and many research results have been achieved. For example, Zhang Jie (2013)[1] analyzed the college students' campus life satisfaction and its influencing factors through factor analysis, and concluded that the school should pay more attention to the students' mental health; Zhao Lin (2012) [2] and other research on the regional differences in the types of higher education quality, pointing out that the influence of educational process factors on student education and school satisfaction is much greater than the students' first factors. $\mathrm{Lu}$ Genshu (2013)[3] conducted a survey of 1,500 college students in China on learning experience, learning style and teaching quality satisfaction through questionnaires, and concluded that improving the quality of teaching should change the existing

This paper is supported by the "Twelfth Five-Year Plan" of the Education Science of Jilin Province (No. GH14219 and GH150287); 2016 Key Research Project of Higher Education Teaching Reform in Jilin Province; 2011 National Education Science "Twelfth Five-Year Plan", "Study on the satisfaction of college students in higher education services" (No. DIA110262). learning style of students and optimize teaching methods.

Postgraduate education is an academic education for cultivating high-level talents. It belongs to the highest stage of higher education and it is the main channel for cultivating highlevel innovative talents. The level of postgraduate education not only affects the ability of higher education institutions to train talents, but also has an important impact on the national education system. Postgraduate education plays an important role in the development of national science and technology, the improvement of productivity and the cultivation of innovative talents[4]. Therefore, vigorously developing postgraduate education is an important measure to improve the country's overall national strength and improve the country's international competitiveness. In recent years, China's postgraduate education has developed at a high speed, and the annual growth rate of graduate students (including professional masters) has exceeded $20 \%$. Under the situation of rapid development of graduate education and diversified training modes, how to ensure the sustainable development of postgraduate education from the perspective of scientific development and effectively guarantee the quality of postgraduate education has become a common concern of the society, and it has also become a focus of scholars. From the market point of view, professional master's education is a process for universities to provide targeted educational products services to students as the main consumer. It can provide students with knowledge-seeking services through the establishment of various professional education projects, courses and so on. At the same time, in the market competition environment, in the face of the competition of other college master's education, colleges and universities must actively explore the satisfaction of the master's education in the school on the basis of improving the quality of their master's teaching, in order to make a comprehensive study of the master's education in the university, thus providing a more scientific reference for the adjustment and optimization of the master's education program.

\section{ANAlysis of Related TheORETICAL ConcePtS}

\section{A. Customer Satisfaction Degree}

Customer Satisfaction Degree (CSD), is an internal subjective reaction of the customer to the service enjoyed by 
the service subject in the process of consumer service. The reaction is based on the most realistic feelings of the customer's heart, and it is difficult to measure it through objective and specific data. The qualitative analysis method can be used to measure and classify the real feelings of the customers before, during and after the process of consumer service from the customer's psychology. And balance the consumption sensation at each stage, the difference between actual satisfaction and expected satisfaction is used to measure customer's actual consumption satisfaction, that is,

\section{$C S D=$ actual perception/expected value}

As far as the subject of this study is concerned, it is actually the final result of the comparison between the actual perception of education received by the master students and their expected educational expectations, which is of representative significance to the quality of master's education in colleges and universities. In order to obtain a better degree of satisfaction and win a good reputation for education, colleges and universities must closely integrate the educational needs of graduate students, through a series of educational services, curriculum settings and improvement, to meet the diverse learning needs of graduate students.

\section{B. Structural Equation Model}

The structural equation model combines multiple structural equations by the combination of structural parameters and random variables on the basis of the factor model. The structural equation model breaks through the limitations of traditional statistical methods that can only perform statistical analysis on actual and single data by virtue of its superiority in statistics. After years of development and improvement, the advantages of the structural equation model have gradually gained the attention and recognition of people in various industries, and it has been widely used in the statistical work of various social industries such as management and economy, which is of great significance to the development of society. In combination with the statistical needs of customer satisfaction, because traditional statistical methods cannot make a comprehensive consideration of customer satisfaction related content, in comparison, the structural equation model can be implicit based on its own advantages. Implicit, ambiguous, comparative, objective, and dynamic fully reflect the characteristics of customer satisfaction.

\section{EMPIRICAL STUDY ON SATISFACTION EVALUATION OF POSTGRADUATE EDUCATION}

\section{A. Questionnaire Design}

In this paper, we collected the data by the school as a unit. After the students fully understand the requirements of the questionnaire, they will answer the questions anonymously. After the completion of the questionnaire, the questionnaire will be collected. After the invalid examination papers are manually eliminated, the final valid questionnaire will be obtained.

The survey was conducted for more than a dozen colleges offering professional master's degree programs. The basic principle is to determine the sample size according to the proportion of postgraduate students in the school. The survey uses the quota sampling method to ensure that the age, gender, and social status of the respondents in each school can accurately represent the graduate students. A total of 1,000 questionnaires were distributed to professional postgraduate students, and 948 were returned. After manual elimination of invalid papers, 926 valid questionnaires, the effective recovery rate was $92.6 \%$. The specific situation is shown in TABLE I.

TABLE I. SURVEY SAMPLE SITUATION

\begin{tabular}{|c|l|c|c|}
\hline & \multicolumn{1}{|c|}{$\begin{array}{c}\text { Sample } \\
\text { distribution }\end{array}$} & $\begin{array}{c}\text { Sample } \\
\text { size }\end{array}$ & $\begin{array}{c}\text { Sample ratio } \\
\text { (\%) }\end{array}$ \\
\hline \multirow{2}{*}{$\begin{array}{c}\text { Master } \\
\text { category }\end{array}$} & Professional master & 615 & 66.41 \\
\cline { 2 - 4 } & Academic master & 311 & 33.59 \\
\hline \multirow{4}{*}{$\begin{array}{c}\text { Interested } \\
\text { in the } \\
\text { profession }\end{array}$} & Very interested & 184 & 19.87 \\
\cline { 2 - 4 } & More interested & 367 & 39.63 \\
\cline { 2 - 4 } & General & 304 & 32.83 \\
\cline { 2 - 4 } & Not interested & 57 & 6.16 \\
\cline { 2 - 4 } & Very uninterested & 14 & 1.51 \\
\hline
\end{tabular}

Through the reliability analysis of the data in the questionnaire, the Alpha reliability coefficients of the four scales of perceptual, feedback, empathy and satisfaction are $0.762,0.823,0.914$, and 0.925 , respectively. According to the judgment criteria, perceptual and feedback are more credible, and empathy and satisfaction are very credible. Judging from this, the internal reliability of the questionnaire is good, and the evaluation results of the questionnaire data in this paper are credible.

\section{B. Principles for Setting the Indicator System}

Based on the structural equation model, the establishment of the professional master's education satisfaction index system needs to fully reflect the objective, real and effective characteristics of each indicator. To this end, in the process of establishing its indicator system, we should strictly in accordance with the following principles [5]:

1. Comprehensive, that is, the selected evaluation indicators must have comprehensive general characteristics, and can comprehensively reflect the overall picture and profile of the analyzed objects;

2. Extensiveness, that is, the selected evaluation indicators are covered in their own fields, and they can involve some related fields to a certain extent;

3. Scientific, that is, the selected evaluation indicators must have certain technical and economic content, and have scientific data processing capabilities;

4. Testability, that is, the selected evaluation indicators are required to be measurable, so as to facilitate the summary of the multi-party data at the end of the satisfaction situation;

5. Simplicity, that is, the selected indicators are less difficult to obtain, and are concise and easy to apply and understand.

\section{Model Framework}

Based on the above principles, according to the comprehensive situation of postgraduate education in colleges and universities, we have developed the following basic model of graduate education satisfaction index system, as shown in Figure 1. 


\section{Customer Satisfaction Index}

In this paper, we use the percentile system to describe the potential variable customer satisfaction index CSI. When the

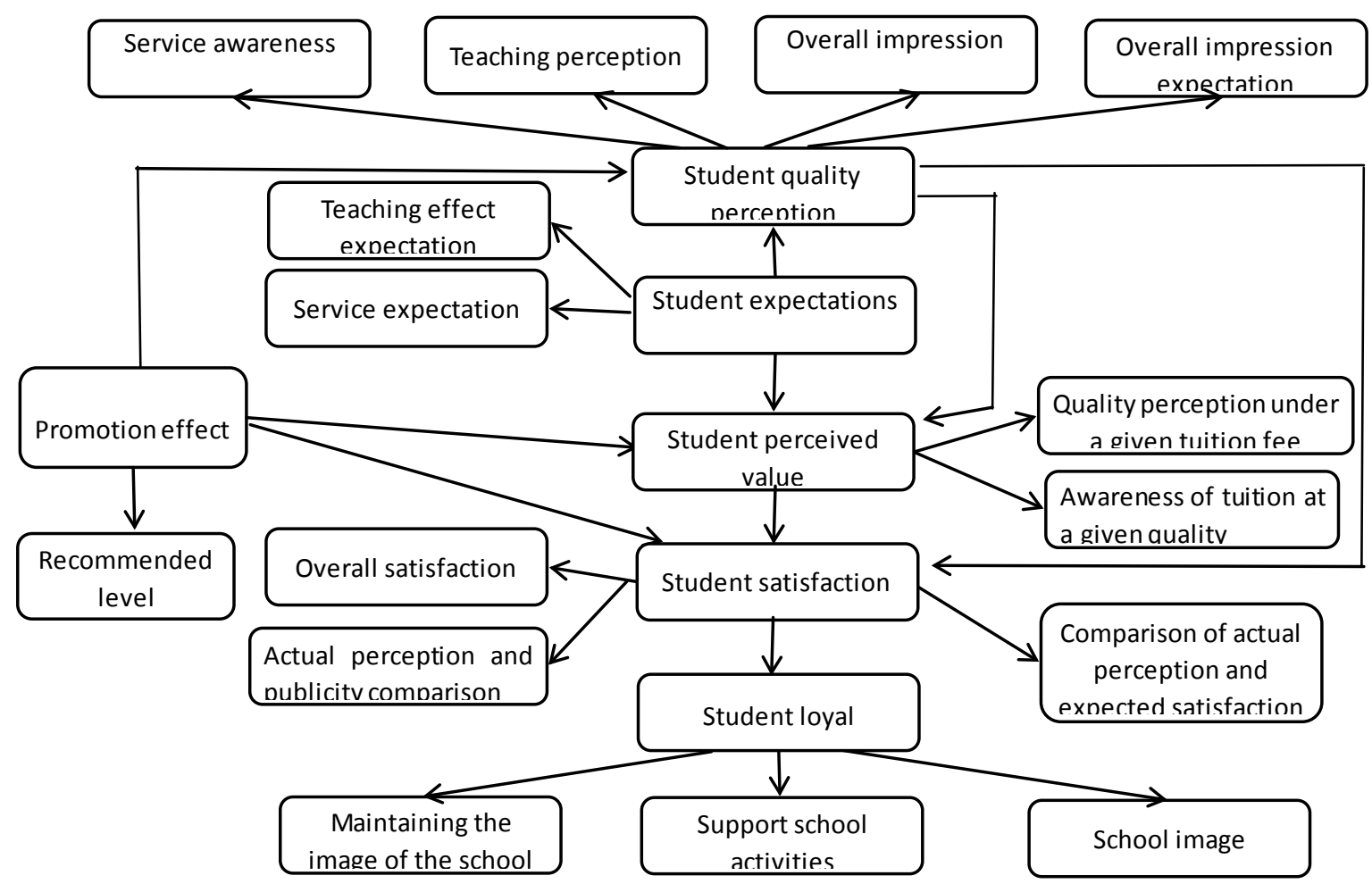

Fig. 1. Structural Model of Graduate Education Satisfaction Index

dissatisfied, take CSI=0; the calculation formula of customer satisfaction index can be expressed as:

$$
C S I=\frac{E[\xi]-\operatorname{Min}[\xi]}{\operatorname{Max}[\xi]-\operatorname{Min}[\xi]} \times 100
$$

Where $\xi$ represents the potential variable customer satisfaction; $\mathrm{E}[\xi], \operatorname{Min}[\xi], \operatorname{Max}[\xi]$ represent the average value of the potential variable customer satisfaction and the minimum and maximum values, respectively.

\section{E. Variable Analysis}

In Fig.1, through the analysis of the relationship among the variables in the structural model above, we can find out the influencing factors of professional master's education satisfaction. This will provide more pertinent and scientific basis for the adjustment and improvement of postgraduate education program in universities. According to the calculation formula of CSI of the previous customer satisfaction index, the student satisfactions index of postgraduate education service in this paper is 62.61, student expectations is 73.28, perceived value is 66.26, and student loyalty is 60.16.

To this end, we select the above two indicators of student expectations and students' perceived value to analyze:

There is a certain relationship between the student expectations and the school's propaganda effect, teaching effect expectation, service expectation and other variables, and through calculation, the relationship coefficient is high, which fully demonstrates that the professional master's teaching to colleges and universities and all aspects of services quality has certain requirements, and the satisfaction of colleges and universities on these requirements will directly reflect their overall perception of college education satisfaction. Based on the essential needs of professional master students in seeking knowledge, students' demand for teaching quality must exist before service needs. Therefore, we can see that the quality of teaching in colleges and universities has a fundamental impact on the educational satisfaction of professional master students.

Given the tuition fee, students' perception of quality is significantly lower than their perception of price, indicating that professional master students are not sensitive to the educational tuition fees of colleges and universities. Therefore, in combination with the essential needs of the above-mentioned master students, the colleges and universities can provide professional master's education. Appropriately raise the tuition level in the context of improving the quality of teaching.

\section{SUGgestions ON IMPROVING THE SATISFACTION OF POSTGRADUATE EDUCATION}

\section{A. Establishing a Teaching Quality Monitoring System}

One of the effective ways to improve the satisfaction of postgraduate education in colleges and universities is to integrate the teaching and management of various resources in colleges and universities, and to build a scientific and rational 
institution of higher learning through the joint efforts of various departments within the institutions of higher learning, using systems theory, cybernetics, information theory and quality management theory. The teaching quality monitoring system forms a stable and efficient system for ensuring the high level of postgraduate education satisfaction in higher education institutions[6]. The construction of teaching quality monitoring system has a positive effect on the improvement of graduate education satisfaction in colleges and universities. For example, the various factors related to the satisfaction of postgraduate education in colleges and universities, information acquisition, timely feedback, and evaluation of the quality of work in each link. Through these positive factors, the satisfaction of professional master's education in colleges and universities can be continuously improved.

\section{B. Improve the Scientific Subject Curriculum}

Postgraduate education needs to cultivate the comprehensive quality of students on the basis of embodying the basic requirements of the country for talent quality. According to the principle of overall optimization, a professional curriculum system is set up to enhance the adaptability, frontier, practicability, intersecting and functionality of the curriculum. At present, some colleges and universities still pay too much attention to the integrity of the discipline itself, while ignoring the students' ability and practice. Therefore, in the curriculum system setting, we must deal with the internal intersection, penetration and integration of the curriculum.

1. Focus on the curriculum system of comprehensive knowledge of subjects. The cross-integration of various disciplines is the main feature of the development of modern science and technology. Based on the overall development and integration of disciplines, the rational construction of a scientific curriculum system and the integration of curriculum content are one of the principles for constructing a new curriculum system[7]. It is necessary to give students comprehensive instructions, focus on the influence of other subject knowledge on the subject itself, and its application in its own field, but also highlight the cross-integration of knowledge and improve the overall optimization of the curriculum system.

2. Identify the core elements of curriculum integration and build optimized curriculum architecture. Effective curriculum optimization and integration can build a learning environment and system that is in line with the coordinated development of students' knowledge, ability and quality. The environment and system need to support real situation creation, effective resource sharing, flexible information acquisition, equal teacher-student interaction, and barrier-free collaborative communication. And it is conducive to cultivating students' creative self-discovery and exploration, and ultimately realizes a kind of research ability and efficiency that can not only play the role of instructors, but also promote students [7].

\section{Improving the Construction of Educational Management Staff in Colleges and Universities.}

The construction of high-quality college education management team is an important guarantee for the improvement of the satisfaction of postgraduate education. To this end, colleges and universities should strengthen the construction of education management staff [8] .Specifically, first of all, for college postgraduate educators, colleges and universities should not only increase the training of faculty and staff in the knowledge structure, but also promote the professional research of professional teachers to improve their own and professional scientific research ability; Secondly, for managers, colleges and universities should actively introduce new management modes such as people-oriented and intelligent management, change the shortcomings of traditional student management, and vigorously promote the realization of the goal of modernization of university masters management; Finally, on the basis of strengthening the management of human resources, colleges and universities should build a scientific evaluation mechanism for personnel work, in order to promote the formation of the scientific teaching management concepts such as student-oriented and lifelong learning in the teaching staff.

\section{ACKNOWLEDGMENT}

This paper is supported by the "Twelfth Five-Year Plan" of the Education Science of Jilin Province, "Evaluation of the Satisfaction of Professional Master Education Based on Structural Equation Model" (No. GH14219); "Cloud-based IT Professional School-Enterprise Joint Experiment Research on the Construction of Teaching Centers (No. GH150287); 2016 Key Research Project of Higher Education Teaching Reform in Jilin Province, "Research on the Training Model of Local University IT Talents Based on International Vision”; 2011 National Education Science "Twelfth Five-Year Plan", "Study on the satisfaction of college students in higher education services”(No. DIA110262).

\section{REFERENCES}

[1] Zhang Jie, Tan Jiandan. College Students' Campus Life Sat isfaction and Its Influencing Factors[J]. Higher Education Research, 2013(1):9-22. (In Chinese)

[2] Zhao Lin, Shi Jingwei, Wang Peng, Wang Wen, Xu Tian. Analysis of the Types and Regional Differences of the Quality of Higher Education in Higher Education[J]. Education Research of Tsinghua University, 2012(5):7-10. (In Chinese)

[3] Lu Genshu. Analysis of the Relationship Between College Students' Curriculum Learning Experience, Learning Style and Teaching Quality Satisfaction[J]. Journal of Xi'an Jiaotong University: Social Science Edition, 2013(2): 96-103. (In Chinese)

[4] Zhang Wei, Wen Xiaowei. Empirical Analysis of Graduate Education Satisfaction Model in Research Universities - Based on the Survey of Six Research Universities in South China[J]. China Higher Education Research, 2014(2): 64-69. (In Chinese)

[5] Li Shuohao, Li Wenping. Research on Higher Education Student Satisfaction Based on Structural Equation Model-Taking 13 Specialized Colleges in Gansu Province as an Example[J]. Journal of Educational Development Research, 2014, 34(7): 36-44. (In Chinese)

[6] Yao Wei. Analysis and Discussion of Innovative Education in Colleges and Universities [J]. China Higher Education Research, 2001(9): 74-75. (In Chinese)

[7] He Qiuyi. Constructing a Reasonable Curriculum System to Realize Scientific Teaching Innovation[J]. Journal of Southwest University for Nationalities: Humanities and Social Sciences Edition, 2004(7):21-26 (In Chinese)

[8] Wang Changce, Mao Quyi. On Management Innovation in Higher Education Innovation[J]. China Metallurgical Education, 2003(6):1-4. (In Chinese) 